\title{
Hydrodynamic Studies on Split Cylinder Reactor: Experimental and CFD Technique
}

\author{
T. Bhalamphiga Arasi ${ }^{1^{*}}$ \\ Department of Chemical Engineering, \\ Kongu Engineering College, Erode - 638060.
}

\author{
K. Saravanan ${ }^{2}$ \\ Department of Chemical Engineering, \\ Kongu Engineering College, Erode - 638060
}

\author{
N. Deepa Priya ${ }^{3}$ \\ Department of Chemical Engineering, \\ Sri Vekateshwara College of Engineering, Sriperumbudur.
}

\begin{abstract}
Split cylinder reactor is one of the kind of airlift reactor in which it is best among multiphase contactors. These reactors are applied in chemical, petrochemical industries, and also in some biological process such as waste water treatment process and aerobic fermentation. In recent days, many of the researcher carried out their study on hydrodynamic and mass transfer characteristics of split cylinder reactor because of several beneficial features such as high and flexible capacity, simple in conceptual design, low shear rate, mixing performance is high, best contact between various phases, reaction time is less, acceptable heat transfer rate, low energy and maintenance cost. Since many reports are discussed about air-water system, in which air is used as a dispersion phase and water is used as a continuous phase. The main objective of this work is to study the hydrodynamic characteristics of split cylindrical airlift reactor using airwater system in both experimental investigation and its simulation using computational fluid dynamics (CFD) techniques. The effect of pressure drop, gas holdup, power on various fluids was investigated. Under various conditions gas holdup was observed at different air flow rates, different bed height and with stirring. It is observed that gas holdup increase with increase in superficial air velocity. It was also noticed that holdup was more with stirrer than without stirrer. Mass transfer Coefficient increases with increase in superficial velocity and stirrer speed. CFD modelling generally offered good agreement with our experimental measurements of the gas hold-up and upwards liquid velocity profiles.
\end{abstract}

Keywords: Split cylinder reactor, hydrodynamic aspects, holdup, CFD.

\section{INTRODUCTION:}

Among the various multiphase contacting reactors, split cylinder reactor plays a major role in recent years, which is one among the type of airlift reactors. These split cylinder reactor is applied to various industries such as chemical, petrochemical industries and also in some of the biological process such as waste water treatment and aerobic fermentation process. Reactor consists of cylindrical acrylic column which is separated as riser and down comer section with a help of a vertical baffle. The compressed air is sparged with the help of sparger in the riser section, which further leads to high gas holdup in riser section and then into downcomer section. Also this high gas holdup helps to reach the desired rate of liquid circulation and also helps to attain high gas-liquid mass transfer rate. ${ }^{(1)}$ Since many reports are discussed about air-water system, in which air is used as a dispersion phase and water is used as a continuous phase. Also some reports explains about the salts, alcohol, surfactants and also in emulsion, that shows different behaviour when they varies their concentration. (2) Hydrodynamic studies in split cylinder reactor is mainly consist of examination of gas holdup, liquid circulation velocity, flow regimes and mixing time. When the circulation velocity of liquids are increased by increasing the ratio of geometrical parameters i.e.,liquid height to diameter is more than 10 and it increases the heat and mass transfer rate in the reactor by increasing the oxygen residence time. ${ }^{(14)}$ The initial rise in the gas holdup with increase in viscosity inside internal loop airlift bioreactors has been related to the lower bubble rise velocity which leads to higher bubble residence time in the riser and a greater entrapment of the bubbles into the down-comer. At the higher viscosity values the higher rate of bubble coalescence has been reported as responsible for the observed decrease in gas holdup with increase in liquid viscosity ${ }^{(16)}$

Mass transfer performance and mixing rate are affected by a parameters called reactor geometry in which it depends on several other parameters such as height to diameter ratio of the vessel, cross-sectional area ratio of riser to downcomer and gas-liquid separator design. ${ }^{13}$ In recent days, many of the researcher carried out their study on hydrodynamic and mass transfer characteristics of split cylinder reactor because of several beneficial features such as high and flexible capacity, simple in conceptual design, low shear rate, mixing performance is high, best contact between various phases, reaction time is less, acceptable heat transfer rate, low energy and maintenance cost.

Conventional airlift reactors are not adequate to carry out variable volume process. Since it is not possible to achieve liquid circulation in this reactor until the liquid height is higher than that of down comer. In order to carry out the process of variable volume, they proposed concept of split cylinder airlift reactor. For enhancing the liquid circulation mixing at any liquid volume, it is advanced it with internals in split cylinder reactor. In this research, the effects of scale 
up on the hydrodynamics of a split cylinder airlift reactor in both riser and down-comer were theoretically studied. For this purpose, the Computational Fluid Dynamics (CFD) soft- ware was applied to obtain gas hold-up in the riser and down-comer. These data were compared with the experimental data obtained for air-water system.

\section{EXPERIMENTAL SET-UP AND METHODS:}

Experimental setup is shown in fig.1. The experimental setup consists of a cylindrical acrylic column of $150 \mathrm{~mm}$ diameter and height of $1000 \mathrm{~mm}$. The column is separated into two sections riser and downcomer zone by using the vertical baffle and their separation ratio is $1: 1$. The baffle is placed in the clearance of $0.2 \mathrm{~m}$ from the base of the column. Sparger is placed in the bottom of the riser side ( $3 \mathrm{~mm}$ and $5 \mathrm{~mm})$. In riser side of the column, support for the packing material is provided for supporting the random packing materials. Packing material of random packing of diameter $13 \mathrm{~mm}$ is used. Impeller(disc turbine) is present in the downcomer side which is run by a motor which is used to enhance the mixing.

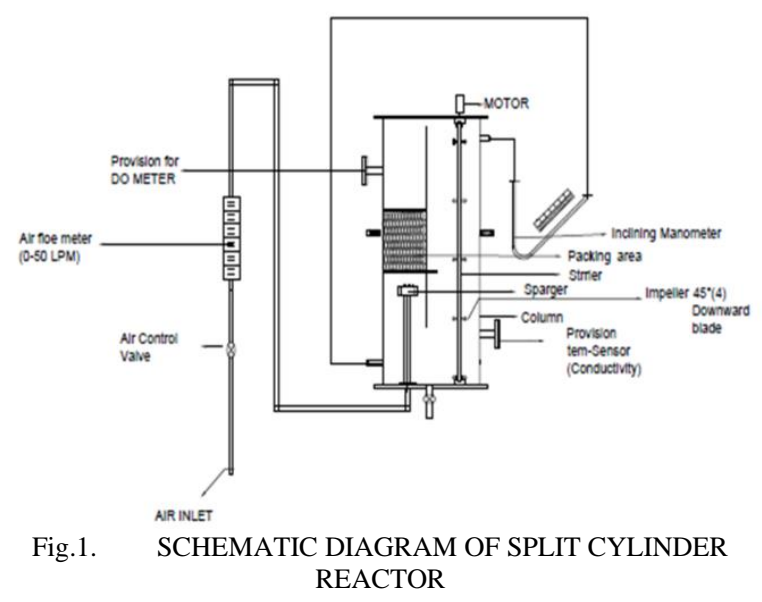

Initially, the column is filled with a textile effluent upto certain level in the column. Note down those height as a initial reading of liquid height. Then, Stirrer is allowed to rotate at a 500rpm constantly. At the same time air is allowed to pass through the column at different airflowrate from the compressor. When column attains the steady state, note down all the corresponding readings in it. Flowrate can be varied and measured with the help of preliminary rotometer (0-50LPM). Pressuredrop across the column is measured with the help of inclined u-tube manometer. Gasholdup is measured by visual observation.

\section{MODELLING}

In this work, the Euler-Euler method and VOF model based on the two- fluid system was applied. Furthermore, each fluid was assumed to be as a continuous phase in each part of the control volume. The phases were dispersed in the interior spaces and diffused within it

\section{SIMULATION}

In the simulation, the gas and liquid phases were air and water, respectively. The governing equations and constitutive relations have been discertized based on the finite element method. At $\mathrm{t}=0$, all of the reactor volume is full of water and the volume fraction of air is equal to zero. The simulation will get steady state after 0 to $10 \mathrm{~s}$. In the current simulation, the Reynolds Stress as Turbulence model and 2D Eulerian model as multiphase model were applied to study the hydrodynamic properties of gas and liquid phases in an internal airlift reactor under unsteady conditions. According to the simulation, the number of nodes was 45000. Boundary conditions for principal equations were assumed without any slip on the walls. For inlet and outlet, the boundary condition was the velocity inlet and the pressure outlet, respectively. The liquid phase was as primary phase and the gas phase was as dispersed phase. Figure 2 shows the distribution of gas 


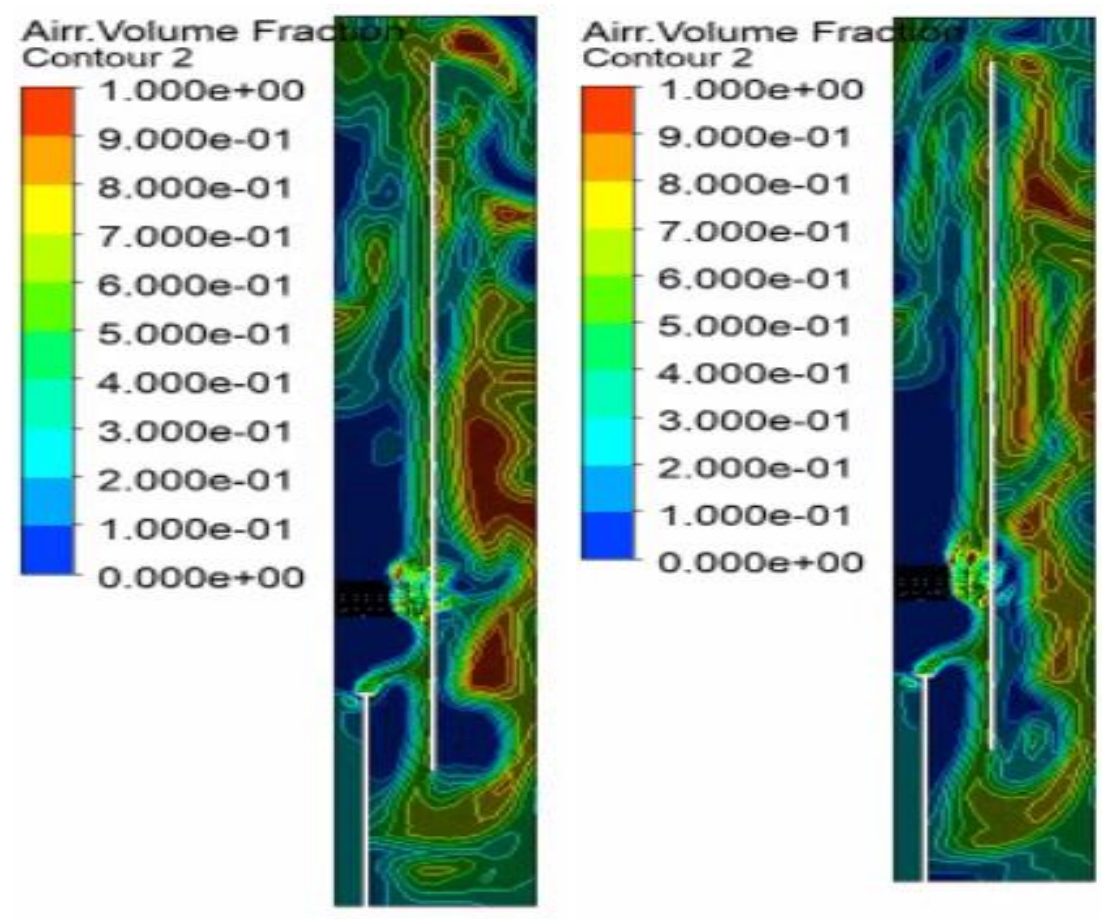

Fig.2.gasholdup distribution in reactor at the superficial velocity of $U g=10 \mathrm{~m} / \mathrm{s}$

\section{RESULTS AND DISCUSSIONS}

In split cylinder reactor, various parameters are analysed by both experimental and CFD technique by changing some parameters such as time, velocity and packing materials. Fig.3. explains the behaviour of split cylinder reactor during various packing materials. Gas hold-up is an important parameter, because it determines the amount of the gas phase retained in the system at any time. Here, when gasholdup increases when sp.velocity of air is also increases. It is clear that structured packing has more gasholdup when compared with random packing. Fig.4. explains about the velocity fluctuation in the column at various time intervals in various sections of the reactors such as top, middle and bottom section using CFD technique.

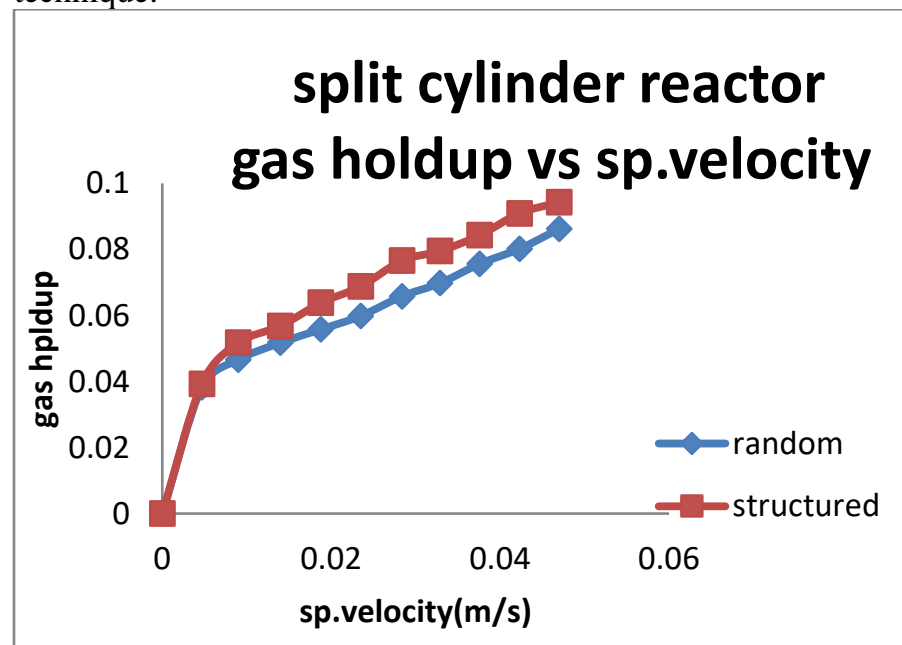

Fig.3. Effect of gasholdup on sp.velocity in split cylinder reactor using Experiemental

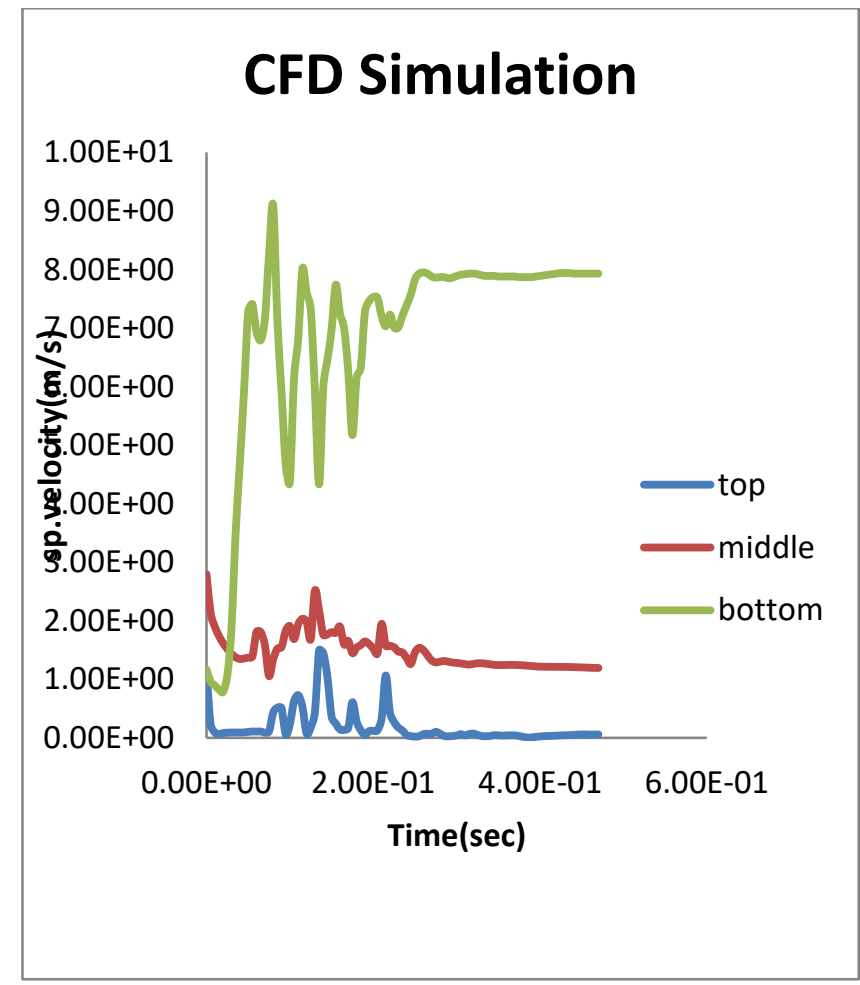

Fig.4. Effect of time on sp.velocity in split cylinder reactor using CFD technique

In Fig.5 explain shows the volume fraction of gas with aera- tion of $10 \mathrm{~m} / \mathrm{s}$ in the reactor in various times (up to steady state condition). As shown in this figure, bubbles rise in the airlift reactor and then bubbles accumulation and gas hold-up occur in it. 

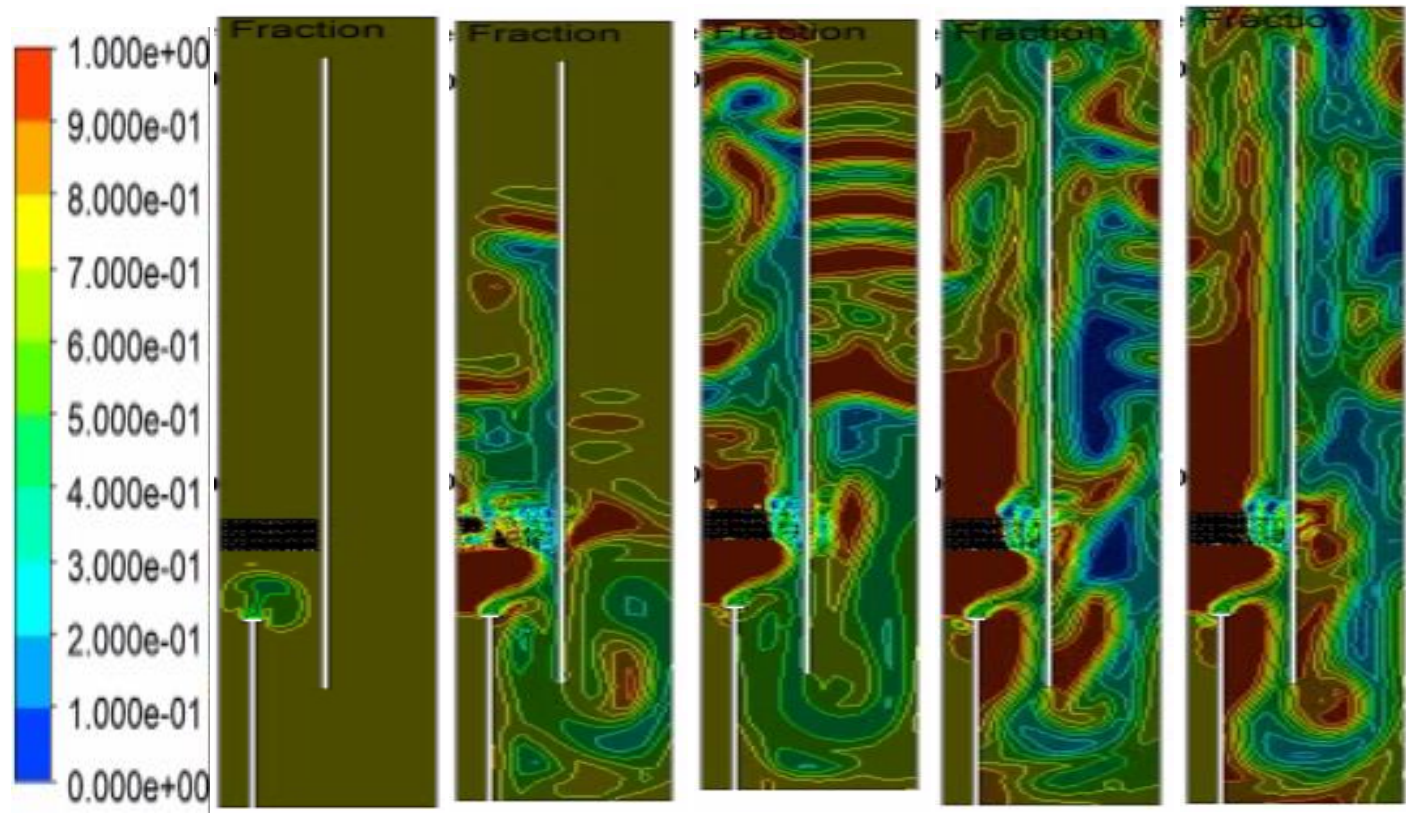

Fig.5. water volume fraction in split cylinder reactor at various time using CFD

\section{CONCLUSION}

In this research, study the hydrodynamic characteristics of split cylindrical airlift reactor using air-water system in both experimental investigation and its simulation using computational fluid dynamics (CFD) techniques. The results showed that the gas hold-up in the riser and downcomer side increased by increasing the superficial gas velocity. Fur- thermore, an increase in superficial air velocity in the riser increased the overall circulation velocity for this reactor.. Therefore, the simulated results were in very good agreement with the experimental data. It was concluded that the CFD is a very useful and accurate tool for scaling-up, as well.

\section{REFERENCES}

[1] Reza Davarnejad, Ehsan Bagheripoor, Abolfazl,and Sahraei.(2012)'CFD Simulation of Scale Influence on the Hydrodynamics of an Internal Loop Airlift Reactor', engineering vol-4.

[2] Dale.D.McClur, Timothy P. Dolton, and Geoffrey W (2017) 'Hydrodynamics and Mixing in Airlift Contactors:Experimental Work and CFD Modelling', Chemical Engineering Research and Design, vol-10.

[3] Mostafa K.Moraveji, Baharak Sajjadi, Reza Davarnejad(2010)'Gas-Liquid Hydrodynamics and Mass Transfer in aqueous alcoholic solution in a split cylinder reactor', Chem. Eng. Technol, vol- 34.

[4] E. Molina, A.Contreras and Y. Chisti (2000) 'Gas holdup, circulation rate and mixing behavior of viscous Newtonian media in a split cylinder airlift bioreactor', IChemE, Vol 77

[5] Mostafa Keshavarz Moraveji, Mohamad Morovati Pasand, and Reza Davarnejad (2012) 'Effects of surfactants on hydrodynamics and Mass transfer in a split-cylinder airlift reactor', the canadian journal of chemical engineering vol-90
[6] K.J. Ganzeveld, Y. Chisti, and M. Moo-Young (1999) 'Hydrodynamic behaviour of animal in split-cylinder airlift bioreactors cell microcarrier suspensions', bioprocess engineering vol-12.

[7] B.Gourich, N. El Azher, and C. Vial.(2006) 'Study of Hydrodynamics, Mixing and Gas-Liquid Mass Transfer in a SplitRectangular Airlift Reactor', the canadian journal of chemical engineering, vol-84

[8] B. Gourich, N. EL Azher, M. Soulami Bellhaj.(2005) 'Contribution to the study of hydrodynamics and gas-liquid mass transfer in a two- and three-phase split-rectangular airlift reactor', Chemical Engineering and Processing vol-44

[9] Mostafa Keshavarz Moraveji , Elmira Mohsenzadeh,Mona Ebrahimi Fakhari.

[10] (2011)'Effects of surface active agents on hydrodynamics and mass transfer characteristics in a split-cylinder airlift bioreactor with packed bed', chemical engineering research and design vol9.

[11] Mostafa Keshavarz Moraveji, Mona Ebrahimi Fakhari.(2012) 'Hydrodynamics and oxygen mass transfer in a packed bed splitcylinder airlift reactor containing dilute alcoholic solutions', Heat Mass Transfer vol- 49.

[12] $\mathrm{Fu}$ wenge, yusuf chisti and murray moo-young. (1999) 'Splitcylinder airlift reactors:Hydraulics and hydrodynamics Of a new mode of operation', Chern. Eng. Comm., Vol-155.

[13] Aastha Ojha (2017) 'Investigation of Local Gas Holdup and Bubble Dynamics using Four-Point Optical Probe Technique in a Split-Cylinder Airlift Reactor', International Journal of Multiphase Flow vol-20

[14] Elmira Mohsenzadeh,Mostafa Keshavarz Moraveji, Reza Davarnejad.(2012) 'Influence of acetaminophen on gas hold-up, liquid circulation velocity and mass transfer coefficient in a splitcylinder airlift bioreactor', Journal of Molecular Liquids vol-173.

[15] P. Ramesh, K. Saravanan (2019)'The Environmental Study on Characteristics Analysis of Packed Bed Split Cylinder Reactor based on Hydrodynamics and Mass Transfer', Ekoloji vol28(107)

[16] Mostafa Keshavarz Moraveji , Baharak Sajjadi, Mahboubeh Jafarkhani. (2011) 'Experimental investigation and CFD simulation of turbulence effect on hydrodynamic and mass transfer in a packed bed airlift internal loop reactor,' 